fournal of Medical Genetics (1974). 11, 253.

\title{
Effects of cystic fibrosis sera on Proteus vulgaris motility
}

\author{
F. L. COHEN* and W. L. DANIEL $\dagger$
}

Summary. Suspensions of Proteus vulgaris were rapidly agglutinated by serum from cystic fibrosis patients. Serum from obligate heterozygotes exhibited a mean agglutination time that was significantly less than that observed for 128 controls. The agglutinating property was observed to be transmitted through several generations and through both maternal and paternal branches of the pedigrees. Qualitative differences were noted, with CF sera inducing the formation of clumps that were two- to 10-fold larger than those observed in heterozygotes. The serum factor responsible for $P$. vulgaris agglutination was heat sensitive, destroyed by pronase, and neutralized by anti-human whole serum. The CF serum retained agglutinating activity following preincubation with anti-human $\operatorname{IgG}, \operatorname{IgA}, B_{1} E$, and $B_{1} A / B_{1} C$.

Persons heterozygous or homozygous for the cystic fibrosis (CF) gene have a serum factor which causes ciliary dyskinesia in rabbit tracheal explants (Spock et al, 1967). Similar results have been obtained using oyster gill cilia (Bowman, Lockhart, and McCombs, 1969), while attempts to employ fresh water mussels (Besley, Patrick, and Norman, 1969; Posselt and Bender, 1971) or chicken tracheal explants (Cherry et al, 1971) have provided mixed responses to the serum factor. Media obtained from short-term cultures of CF leucocytes have also been found to inhibit the cilia of rabbit tracheal explants. The dyskinetic effect was inhibited by addition of rabbit antiserum to human IgG (Conover et al, 1973). The inhibitory factor has been observed to be associated with IgG during chromatographic fractionation of CF sera (Bowman, McCombs, and Lockhart, 1970; McCombs and Bowman, 1970; Schmoyer, Fischer, and Brooks, 1972).

Development of an effective screening programme for cystic fibrosis and its carrier state has been impeded by lack of an efficient test system that can be made readily available to clinical laboratories. The tests currently dependent upon increased sweat sodium are not able to detect the heterozygous state

\footnotetext{
Received 10 December 1973

* University of Illinois, College of Nursing, 1400 W. Main St., Peoria, Ill 61606, USA.

+ School of Basic Medical Sciences and Department of Zoology, University of Illinois, Urbana, Ill 61801, USA.
}

with sufficient accuracy. Although the ciliary inhibition systems appear adequate for carrier detection, they have geographical or temporal limitations or would be difficult to employ on a mass screening basis. We report an assay using a bacterial system that has proved effective in detecting both $\mathrm{CF}$ patients and carriers and which could be adapted to screening programmes.

\section{Materials and methods}

Venous blood samples were obtained from 18 cystic fibrosis patients attending a local clinic, 30 obligate heterozygotes, 107 hospitalized patients without cystic fibrosis, and 21 university students in good health. The specimens were allowed to clot, and the serum was aspirated following centrifugation at $4150 \mathrm{~g}$ for 10 minutes. Sera were stored at $4^{\circ} \mathrm{C}$ and were used within 48 hours of collection.

Proteus vulgaris was maintained at $4^{\circ} \mathrm{C}$ on nutrient agar (Difco) until use. Before assay a loopful of $P$. vulgaris was transferred to $20 \mathrm{ml}$ of nutrient broth (Difco) and incubated at $37^{\circ} \mathrm{C}$ until an active motile log phase was attained. The absorbance of the suspension at $500 \mathrm{~nm}$ was 0.30 to 0.40 . One drop of suspension and one drop of serum were dispensed from a Pasteur pipette onto a microscope slide, covered with a cover slip, and examined for agglutination at $\times \mathbf{4 0 0}$ magnification at 2 -min intervals.

The effects of a variety of treatments on the agglutinating properties of CF sera were studied in parallel experiments. $\mathrm{CF}$ and carrier sera were preincubated at $56^{\circ} \mathrm{C}$, 
and aliquots were withdrawn at 3-, 5-, and 10-min intervals and assayed for agglutinating activity. The effect of pronase upon the agglutination of $P$. vulgaris was determined by preincubation of $1 \mathrm{ml}$ serum with $1 \mathrm{ml}$ of pronase (Calbiochem) in $0.85 \%$ sodium chloride $(2 \mathrm{mg}$ / $\mathrm{ml}$ ) for one hour at room temperature. A control of $2 \mathrm{mg}$ pronase per $\mathrm{ml} 0.85 \%$ sodium chloride was employed to assess direct action of the enzyme on the flagellar bacteria. Immunological inactivation of the agglutinating factor was attempted by pretreatment of pooled CF sera with commercially prepared antisera (Behring Diagnostics) against human whole serum, $\operatorname{IgA}, \operatorname{IgG}, B_{1} E$, or $B_{1} C / B_{1} A$ fractions.

Serum: antiserum ratios in the range of $1: 2$ to $1: 50$ were tested for neutralization of the agglutinating factor.

\section{Results}

Exposure of Proteus vulgaris suspensions to cystic fibrosis sera resulted in rapid agglutination with a mean time of $3.9 \pm 1.8$ minutes (Table I).

TABLE I

Proteus vulgaris AGGLUTINATION BY DIFFERENT SERUM TYPES

\begin{tabular}{l|c|c}
\hline \multicolumn{1}{c|}{ Sera } & Number & $\begin{array}{c}\text { Agglutination Time } \\
(\mathrm{min})^{*}\end{array}$ \\
\hline $\begin{array}{l}\text { Cystic fibrosis } \\
\text { Obligate } \\
\text { Heterozygotes }\end{array}$ & 18 & $3.9 \pm 1 \cdot 8$ \\
Controls & 128 & $6 \cdot 2 \pm 3.4$ \\
\hline
\end{tabular}

Scheffé Analysis of Means

Cystic fibrosis: Obligate heterozygote $\mathrm{p}<0.001$

Cystic fibrosis: Controls

Obligate heterozygote: Controls $\quad \begin{aligned} & \mathrm{p}<0.001 \\ & \end{aligned}$

* Mean \pm SD.

Similar preparations from obligate heterozygotes exhibited a mean agglutination time of $6 \cdot 2 \pm 3.4$ minutes. The mean agglutination time for the non-CF patients and university students was $23.6 \pm$ 10.6 minutes. In many of the slow reacting serum preparations the aggregation of $P$. vulgaris was most likely due to drying effects rather than to intrinsic properties of the sera employed.

Qualitative differences among the effects of the various serum types upon $P$. vulgaris motility were also observed. Cystic fibrosis serum precipitated the formation of large aggregates of bacteria. Clumps of this size were not observed in either obligate carrier or control preparations. Parents of CF patients tended to fall into two groups. Twelve of the heterozygote preparations had cell aggregates which were about half the size of those observed in CF preparations. The remaining 18 carriers exhibited a weaker reaction in which the clumps were approximately one-fifth to one-tenth the size of the CF aggregates. Ten of the hospitalized, non-CF

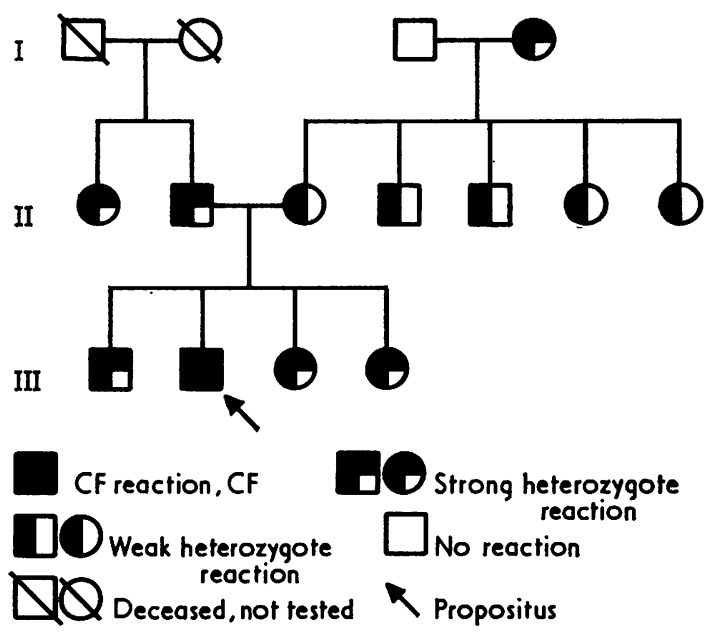

FIG. 1. Transmission of agglutination response in family $\mathbf{R}$.

patients and one of the university students overlapped the heterozygote distribution. Six of these were indistinguishable from the 'strong' heterozygote reaction and five exhibited the 'weak' heterozygote reaction.

Studies of CF families suggest that the agglutination response may have a genetic basis (Fig. 1). In each kindred investigated, the agglutination ref sponse could be traced through two or more genera? tions of the maternal and paternal branches of the pedigrees.

Pretreatment of CF or carrier serum with pronase inhibited the agglutination response. Preincubation of $\mathrm{CF}$ or carrier serum at $56^{\circ} \mathrm{C}$ also destroyed its agglutinating activity. When CF sera were frozen and thawed more than once, agglutinating activity was lost. Exposure of pooled CF sera to anti-IgA, anti-IgG, anti- $B_{1} E$, or anti- $B_{1} C / B_{1} A$ failed to alter the agglutinating response. Preadsorption of CF sera with anti-human whole serum removed its ability to clump $P$. vulgaris cells.

\section{Discussion}

The serum agglutinating factor observed in cystic fibrosis patients appears to be a protein. Low levels of this protein may exist in normal sera since rabbit antiserum against intact human serum blocks the agglutinating response. The serum factor does not appear to be associated with $\operatorname{IgG}, \operatorname{IgA}$, or the complement fractions since specific antisera against these fractions failed to inhibit the agglutination properties of CF sera. The dyskinetic factor described by Bowman et al (1970) could not be separated from IgG by chromatographic techniques. 
Schmoyer et al (1972) have tentatively identified the dyskinetic factor as an immunoglobulin; however, it is possible that the precipitin band obtained with anti-IgG was due to contaminating protein. The possibility that the dyskinetic factor is a nonimmunoglobulin cannot be excluded at this time.

Heparin inhibits the ciliostatic effect of CF serum (Doggett, Harrison, and Patrick, 1973). The antidyskinetic effect was paralleled by an increase in turbidity which could be attributed to precipitated amylase. The authors cited increased amylase levels in CF saliva and implicated this enzyme as the dyskinetic factor. Litt, Khan, and Kwart (1971) detected a second component that exists in CF saliva that causes an initial decrease in the zeta potential of mucus. Current data relevant to the effects of either amylase or the basic polypeptide on $P$. vulgaris motility are insufficient to provide further insight into these interesting discoveries.

The identity of the ciliary dyskinetic factor and our agglutinating factor has not been demonstrated; however, this is a strong and attractive possibility. If identity is eventually proven, the Proteus system may possibly substitute for the oyster or rabbit systems as a screening tool.

When CF, heterozygote, and control samples were coded and then assayed in a blind study, all of the CF specimens were correctly identified. None of the heterozygote or control specimens were misclassified in the CF group.

Approximately one in 12 control serum specimens agglutinated the $P$. vulgaris preparations. Goodman and Reed (1952) estimated the cystic fibrosis carrier frequency as 1 in 20 to 1 in 16. However, more recent studies suggest that an incomplete manifestation of cystic fibrosis may exist in the adult population which masquerades as chronic bronchitis, emphysema, peptic ulcer, or bronchiectasis (Latts, Cummins, and Zieve, 1956; Zasly, Baum, and Rumball, 1960; di Sant'Agnese and Powell, 1962). The relatively high incidence of positively responding control specimens may reflect the higher estimate of the carrier frequency implied by these studies. The possibility that Proteus or other infectious diseases may give rise to false positives cannot be excluded at this time. Such infections would be expected to cluster in time rather than continue through a series of generations. Furthermore, many pedigrees had contiguous sibs who differed in strength of their agglutinating capacity-one normal and the other with strong or weak agglutination tendency. These observations contra-indicate an association between $P$. vulgaris infection and the agglutinating properties of CF and carrier sera. Studies utilizing institutionalized patients with known Proteus infections are currently in progress to further evaluate this potential source of error.

The variability of the clinical symptoms of cystic fibrosis suggests that the genetics of the disease may be more complicated than previously believed. A two-locus model could explain the heterogeneity of clinical signs and also account for the two types of obligate heterozygote reactions revealed by the Proteus system.

The clinically affected individuals may be represented:

$A_{2} A_{2} B_{2} B_{2}, A_{2} A_{2} B_{1} B_{2}, A_{1} A_{1} B_{2} B_{2}$-severe cystic fibrosis (pulmonary and pancreatic symptoms). $A_{2} A_{2} B_{1} B_{1}$-cystic fibrosis (pancreatic symptoms predominating).

$A_{1} A_{1} B_{2} B_{2}$-cystic fibrosis (pulmonary symptoms predominating).

$A_{1} A_{1} B_{1} B_{1}$-normal.

The obligate heterozygotes may have the following genotypes:

$A_{1} A_{2} B_{1} B_{2}$-'strong' carrier reaction.

$A_{1} A_{2} B_{1} B_{1}$ or $A_{1} A_{1} B_{1} B_{2}$-'weak' carrier reaction.

The $P$. vulgaris system has potential as a screening method for both cystic fibrosis and the CF carrier state. Adaptation of this assay system to spectrophotometric analysis is currently in progress. If successful, the test could be rapidly performed on a large number of people at low cost and with increased accuracy compared to present methods. The Proteus system may also prove of value in further clarifying the genetic component of the clinical heterogeneity observed in cystic fibrosis patients.

We thank Dr David Pittman for supplying the Proteus vulgaris used in this study, Mrs Donna Tipton for her cooperation in contacting the cystic fibrosis patients and their families, and Miss Joyce Yeast.

\section{REFERENCES}

Besley, G., Patrick, A., and Norman, A. (1969). Inhibition of the motility of gill cilia of Driessensia by plasma of cystic fibrosis patients and their parents. Fournal of Medical Genetics, 6, 278280.

Bowman, B., Lockhart, L., and McCombs, M. (1969). Oyster ciliary inhibition by the cystic fibrosis factor. Science, 164, 325326.

Bowman, B., McCombs, M., and Lockhart, L. (1970). Cystic fibrosis characterization of the inhibitor to ciliary action in oyster gills. Science, 167, 871-873.

Cherry, J., Roden, V., Rejent, A., and Dorner, R. (1971). The inhibition of ciliary activity in tracheal organ cultures by sera from children with cystic fibrosis and control subjects. Fournal of Pediatrics, 79, 937-942.

Conover, J., Beratis, N., Conod, E., Ainbender, E., and Hirschhorn, K. (1973). Studies on ciliary dyskinesia factor in cystic fibrosis. II. Short term leukocyte cultures and long term lymphoid lines. Pediatric Research, 7, 224-228. 
Di Sant'Agnese, P. and Powell, G. (1962). Eccrine sweat defect in cystic fibrosis of the pancreas (mucoviscidosis). Annals of the New York Academy of Sciences, 93, 555-599.

Doggett, R., Harrison, G., and Patrick, T. (1973). Cystic fibrosis: in vivo reversal of the ciliostatic character of serum and parotid secretions by heparin. Nature New Biology, 243, 250-252.

Goodman, H. and Reed, S. (1952). Heredity of fibrosis of the pancreas. Possible mutation rate of the gene. American fournal of Human Genetics, 4, 59-71.

Latts, E., Cummins, J., and Zieve, L. (1956). Peptic ulcer and pulmonary emphysema. Archives of Internal Medicine, 97, 576-584.

Litt, M., Khan, M., and Kwart, H. (1971). Parotid secretions in cystic fibrosis. Effect on zeta potential of tracheal mucus. Biochemical and Biophysical Research Communications, 43, 919-926.

McCombs, M. and Bowman, B. (1970). Rivanol treatment of cystic fibrosis serum. Effect of supernatant upon ciliary action. Clinical Genetics, 1, 171-176.

Posselt, H. and Bender, S. (1971). Heterozygote testing in cystic fibrosis. Experimental studies with cilia of the mussel Dreissena polymorpha. Zeitschrift fïr Kinderheilkunde, 110, 93-98.

Schmoyer, I., Fischer, J., and Brooks, S. (1972). Fractionation of oyster cilia inhibitor from cystic fibrosis heterozygote serum. Biochemical and Biophysical Research Communications, 46, 19231927.

Spock, A., Heick, H., Cress, H., and Logan, W. (1967). Abnormal serum factor in patients with cystic fibrosis of the pancreas. Pediatric Research, 1, 173-177.

Zasly, L., Baum, G., and Rumball, J. (1960). The incidence of peptic ulceration in chronic obstructive pulmonary emphysema: a statistical study. Diseases of the Chest, 37, 400-405.

\section{Human Blood Coagulation Nomenclature}

A new genetic nomenclature for human blood coagulation has been developed by a working party of the International Committee of Haemostasis and Thrombosis. This new nomenclature attempts to rationalize the phenotypic and genotypic descriptions of the known genetic disorders of coagulation and haemostasis. Authors are now requested to use this nomenclature when submitting manuscripts. The new nomenclature is described in detail with several examples in: Graham, J. B., Barrett, D. A., Blombäck, B., Cann, H. M., Hardisty, R. M. Larrieu, M. J., and Renwick, J. H. (1973). A genetic nomenclature for human blood coagulation. Thrombosis et Diathesis Haemorrhagica, 30, 2-11. 